alongside mine in a digital edition of MobyDick that gives readers immediate access to the text's revision sites. Such an edition would also provide users with tools that would allow them to contribute plausible revision narratives of their own, either in a "sandbox" for pedagogical purposes or, with editorial approval, in the edition itself. Funded by the National Endowment for the Humanities, the Melville Electronic Library is developing a tool, called TextLab, that will follow reliable editorial protocols and enable critical discourse.

Let me conclude by addressing a point Ketterer raises in his opening paragraph. He asserts that fluid-text editing of Frankenstein would not be worthwhile "if it cannot conclusively determine the composition order of the two major surviving portions of the draft manuscript." My own work on the working draft of Typee, which eventuated in an electronic edition of that fluid text, gives me some inkling of the problem Ketterer addresses. Revisions in manuscript most surely occurred in one, and only one, way; but that historical sequencing is no longer precisely determinable. But while we cannot "conclusively determine" a particular revision sequence, we can nevertheless discuss alternative possibilities just as editors have argued for centuries the viability of one variant over another. In this regard, no critical edition-fluid-text or otherwise-can purport to be conclusive. Editing is a field of discourse, and fluid-text editing is a sphere of inquiry that enacts the discourse on texts in revision. But to discuss revision, readers need easy and reliable access to revision sites so that they can articulate possible sequences and narrate them. Only by doing so can readers gain purchase on how texts evolve.

John Bryant

Hofstra University

\section{Fat Subjects on PMLA Covers}

\section{To THE EDITOR:}

On the covers of two recent issues of PMLA-May 2009 (124.3) and January 2011 (126.1) - you've printed images of fat subjects, but in the five years I've been a member of the MLA I have yet to see scholarship in PMLA or at the MLA Annual Convention that represents the emerging field of fat studies. It is a shame that while fat subjects are used to entice the reader into the pages of PMLA, the critical interventions that fat studies scholars are doing in the field of literature and culture, among other topics, are absent from PMLA.

I want to believe that $P M L A$ is not using fat images as "freakery," a spectacle that titillates the reading audience, rendering the fat person voiceless, missing from engaged scholarship in literature and language. I hope that the next time I see an image of a fat person on the cover of PMLA, it is because the journal has devoted a special issue to fat studies.

Julia McCrossin George Washington University 